\title{
Understanding community: \\ thoughts and experiences of young people online
}

\author{
Hilary Yerbury
}

\begin{abstract}
This ethnographic study of members of Generation X and Generation Y seeks to explore the ways they understand and experience community. Their comments and stories were gathered through interviews collected towards the end of 2006 and the early part of 2007. These provide richly textured evidence of their need to belong, to maintain everyday relationships and to collaborate with others at the same time as they commodify relationships or share information but not necessarily beliefs and values. Consequences of globalisation such as individualisation, transience in relationships, immediacy in communication, the blurring of boundaries between work and leisure, between public and private and the reliance on information and communication technologies are part of their everyday lives. Some study participants feel dis-embedded from their traditional social relationships and seek to establish new ones, whereas others feel comfortable joking with anonymous others. Their intellectualised constructs of community and descriptions of the lived reality of community find reflections in a range of theoretical constructs in the literature, both reinforcing and shifting scholarly understandings of the concept of community.
\end{abstract}

\section{Introduction}

In spite of the predictions of scholars in the 1960s and 1970s that the concept of community was obsolete (Bell \& Newby 1974) community is still the focus of many studies; it also appears to be a concept we cannot live without. Zygmunt Bauman comments that community is something we consider fondly, it is the 'kind of world which is not, regrettably, available to us - but which we would dearly love to inhabit and which we hope to re-possess' (2001, p. 3). Significant changes have affected the world we live in since the late twentieth century, impacting on the relationships we have with others and potentially leading to new forms of association. Some of these changes have been fostered by changes in communications technologies, such as the widespread use of the Internet and phone technologies. These have made the world seem smaller by compressing time and space and they have turned some of what was extraordinary into the commonplace. In such a world, people can expect to move between countries to live, study and work, and form social relations wherever they are, communication technologies can keep them connected, no matter where they are at any given time, thus leading to a sense that social relations exist across the world, independent of physical location and face to face interaction. At the same time, these 
changes are perceived to put social relations under strain, weakening face to face connections and undermining the social fabric of community and associational life.

Some writers have acknowledged these changes by modifying the term 'community'. Appadurai (1990) has explored the notion of the diasporic community and the efforts that people make using information and communication technologies to overcome the dislocations of being spread around the world. Rheingold (1994) introduced the phrase 'virtual community' to encapsulate the notion of an environment where people create a sense of community but without a physical location and without embodied co-presence. Others such as Cohen (1985) and Anderson (1983; 1991) have suggested that the focus of the term community itself has shifted. Others again, such as Wittel (2001), have proposed that the very nature of the relationships inherent in community have changed.

This study seeks to investigate the ways in which the intellectualised constructs of community and descriptions of the lived reality of community find reflections in a range of theoretical constructs in the literature, both reinforcing and shifting scholarly understandings of the concept of community. Its particular concern is with the understandings and conceptualisations that young people have, exploring the assertion that, as a concept, community is obsolete. The question is significant because, without ways to understand lived realities and conceptualise them, the opportunities for rethinking social relationships are limited. The paper presents an overview of the literature, presenting shifts in the conceptualisations of community. It briefly describes the methodology before setting out the range of conceptualisations found in the descriptions participants give of their lived experiences and in their intellectualisations of community. Its conclusion returns to the question of whether community as a concept is obsolete and what this might mean for contemporary scholarship and for civil society.

\section{Community - A solid core and fuzzy boundaries?}

The concept of community has been variously described as having a 'solid core' and 'fuzzy boundaries' and the use of these terms symbolises the conceptual issues from the past. The term 'fuzzy boundaries' uses the metaphor of location to express the idea that the concept of community is not experienced in the same way by everyone. Originally, 
it was used more literally to indicate that members of a locally based community interacted with individuals from outside of that community. Now, the same phrase is used to indicate that the very ideas that make up the notion of community interact with other ideas, that different terminology is used and at the edges, there may not be agreement that a word or an idea is actually a part of the notion of community. The metaphor of the 'solid core' suggests something unyielding, unchangeable, dependable and expresses that there is something essential to the notion of community. The 'solid core' usually refers to a sense of something shared - ideas, beliefs, values, information. It also incorporates a notion of togetherness, as community is as much a process as an entity. The ideas behind these two different metaphors pervade the contemporary literature.

There is a strong scholarly tradition supporting the notion that community can only be known or explored by being inside it and focusing on others who are also or who could be inside. The 1990s were seen as times of uncertainty, when people began to oppose the fragmenting effects of liberalism and capitalism and to re-think the values which guided public and private life. A renewed emphasis was placed on the importance of sharing and a number of books and articles focusing on communitarianism and supporting the notion of civil society were published (eg Etzioni 1995, 1997; Putnam 2000). The focus of these works was a lament for the potential loss of values and a sense of insecurity for the future. Putnam’s writing brought the phrase 'civil society' into popular use and sparked reconsideration of notions such as democracy, the role of government agencies and non-government agencies and reinforced ideas that through associational membership people could take part in activities of civic engagement (Putnam 2000).

Anthony Cohen argued that community still existed and had not been rendered 'obsolete' by the various changes and challenges (1985, p. 117). He proposed that the most effective way to understand the notion of community is to understand how people use it, not to analyse its structure from the outside, but to look outwards from its core [emphasis in the original](1985, p. 20). He argued that 'people construct community symbolically, making it a resource and repository of meaning and a referent of their identity’ (1985, p. 118). Drawing on the work of Schwartz, Cohen explored the relationship between community and identity, suggesting that people find both 
commonality and difference in their 'occupancy of the community's social space'(1985, p. 109) and that through their outward focus, they become aware the boundaries which separate them in their community from others, outsiders. Thus, for Cohen, the term, community, marked both belonging and exclusion, symbolising both the groups' solidarity and its contrasting identity and relationships with other groups. It was this contrasting which 'makes the notion of 'boundary' so central to an understanding of community'(1985, p. 109).

\section{Shifting the boundaries}

Benedict Anderson's books, entitled Imagined Communities: the Origins and Rise of Nationalism, (1983; 1991) popularised the phrase ‘imagined community’ and were important for the conceptualisation of community as he showed how a sense of relationship could be established through the sharing of ideas. In particular, he showed how what people read and what ideas they share can shape a community or a nation. Although Anderson's starting point was the introduction of printing with movable type in Europe and its contribution to the creation of nationalism, and he was concerned with instruments such as legislation, the census, museums and mapping, the principles have carried across easily to the impact of other media which link together people who may never know each other in person irrespective of any geographic relationship. The widespread availability of information and communication technologies has changed the ways in which people relate to each other, helping to remove barriers of time and place as people read the same media content, listen to the same music, see the same video clips and experience similar marketing and other policy strategies.

Information and communication technologies have changed the ways that people interact. There are many descriptive studies of group processes and communications supported by computer networks and the term, virtual community, denoting such groups rapidly entered into everyday speech. Rheingold (1994) takes this idea of using information technologies to create community further and claims that community, by which he means affiliation, support and a sense of belonging, can exist online among people who are not linked in other ways except by interest. For him, '[v]irtual communities are social aggregations that emerge from the Net when enough people carry on ... public discussions long enough, with sufficient human feeling, to form webs 
of personal relationships in cyberspace' (1994, p. 5). This definition from Rheingold carries echoes of the work of Clifford Geertz (1993) and shows the close relationship between community and culture.

\section{Different forms of relationships}

Albrow and Eade (1994) noted that the theoretical problems with the concept of community have not been resolved, but the focus has shifted because of the deterritorialisation brought about by globalisation. Writers such as Appadurai (1990) have studied ethnic minorities and local communities in Britain and have introduced the notion of the diasporic community, where formerly integrated and potential close-knits groups of people related by ethnicity or language, have moved or been re-located to many different communities, but have still managed to maintain social interactions and maintain a sense of community. Appadurai is concerned with a sense of continuity, whereas Giddens focuses on the separation and the re-embedding, which brings about new relationships. He has approached the issue of changes in the nature of community from the perspective of the wider society, proposing that social relationships could be 'disembedded' and still continue to exist regardless of the constraints of time and place (1990).

Albrow and Eade (1994) create a parallel between the concept of community and the concept of culture. They note that this relationship between community and culture was inherent from Tönnies’s distinction between Gemeinschaft and Gesellschaft (1974). It shifted when Raymond Williams argued that culture could have three meanings: culture as the process of human perfection; culture as high culture and culture as a way of life. Williams's definition of culture as a way of life was first published in 1961 and this conceptual development strengthened the link between culture and community for many writers (1961), including Clifford Geertz. Albrow and Eade imply that it is culture that is the core of the dispersed and polycentric new forms of association, 'with different temporalities and spatialities, fleeting forms of encounter, in which dense and varied meanings flow'(1994, p. 28). 


\section{A form of association?}

Wittel argues that a new form of association is emerging, which can be understood in its contrast to community and which will become 'the paradigmatic social form of late capitalism' (2001, p. 71). He dubs this network sociality and links it to the disembedded social relationships identified by Giddens, where the focus is likely to be on exchanging information or 'catching up’(2001, p. 51). He proposes that network sociality comprises five features. Individualisation, a consequence of the disintegration of traditional community, means that people have to create their own relationships with others, developing social bonds through work or through their interests and constantly maintaining them. Transience and intensity in social contacts, fostered by the ease of travel and possibly stemming from a work-based focus on projects, means that people rarely spend much time with others. Closely related to the consequences of social interactions existing around the demands of mobility and time pressures is the shift to a focus on information, a mode of communication which is quick and focused but which has no place for stories, for narratives created over time. The fourth feature is the blurring of boundaries between work and leisure time, with work contexts becoming playful and work colleagues being seen as friends. The fifth feature is technology, without which the de-localised interactions of network sociality would not be able to take place. These include transport, information and communication technologies and those technologies which support relationships with friends and colleagues, replacing address books.

\section{Methodology}

This ethnographic study explores the views of twenty-four young people on what community is and how it is created both through the use of information and communication technologies and 'in real life'. It presents their views on community as an intellectual construct and as an aspect of social life. The participants were identified through a snowball technique, which began initially with four people aged in their late twenties or early thirties. These were selected because of their involvement with civil society and actions for social change and their use of online information and communication technologies. When several participants noted that those five or so years younger than them would have a different perspective on community and online interactions, a fifth snowball was begun, initiated by a twenty-one year old. Thus the 
participants were all members of so-called Generation X and Generation Y. Twenty three participants were interviewed face to face in Sydney or Canberra between September 2006 and April 2007 and the twenty fourth, who was overseas, responded by e-mail. The participants were all highly-educated, with some having already completed masters degrees or honours and the rest still studying at undergraduate level; nine were female and fifteen were male. .Although data on ethnic origin was not collected, it was apparent from physical and social characteristics that almost half (11/24) are not of Anglo-Celtic origin.

The unstructured interviews invited participants to explore their understandings and experiences of community and of civil society and raised questions of whether these understandings and experiences were similar online and offline. Each interview lasted approximately one hour, was recorded using an MP3 player and subsequently transcribed. The transcriptions were analysed and pattern coded using NVIVO's free node function.

There is no single view of community, expressed by the young people who took part in this study, yet all are able to define community, presenting a view of it as an intellectual construct, and to describe or comment on techniques which foster its creation or development or factors which harm it online and offline.

\section{Intellectualising community}

Participants in the study intellectualise the concept of community. The responses to the question of what community meant often sounded like the answer to an examination question of the 'short answer' type. Rachel acknowledged this notion of the learned response with her exclamation of 'Ah, the biggest question!'

For Tom, community has a social focus, perceived by those who are part of the group. 'A community is a group of people who self-identify. They have something in common, whether that's an interest or a geographic location.' For Anna J., on the other hand, community is based on common interest or collaborative action. 'Community is people coming together to share a common interest or to support one another or to do activities with the aim of reaching a common goal.' 
Angela described community as:

'a group of people who have certain things in common, which are information, [connection] with each other and general support as well, in a general sense that's what I think community is'.

Isaac began with an apparently learned response before pausing and commenting:

'it's really hard [to answer] because you can be part of many communities at the same time and communities overlap and they can interact with each other in quite diverse ways, so it's quite a broad question really, so it's hard for me to answer'.

Isaac's comment indicates that not only does he acknowledge multiple definitions of community and the existence of many communities, but also that a single individual can belong to more than one community.

Annette, in measured tones, acknowledged that whatever answer one gave, any definition of community could be contested:

'I think it's difficult [to state a definition] because there has been a lot of academic debate about it and there's a lot of debate in different communities about what it means to belong to one or to another. For me, it's about a sense of belonging, about being with people that you have some sense of familiarity with and shared values and shared identity, a sense of recognition and of being able to be that identity within that space in quite a comfortable way.'

All but two of the participants seemed to look inward towards 'people that you have some sense of familiarity with ... a sense of recognition' (Annette). Alastair and Brett both took the opposite view. Brett observed that 'it can collectivise us because we have a common enemy' and Alastair noted:

'Community can form around people hating each other's guts because then you get the supporters and the peacemakers and all the various ecological niches of 
human beings that make up any society, fitting around a schism in their community'.

\section{Living community}

Throughout the interviews, participants in the study gave examples from their own backgrounds and experiences, which in many instances gave a clear picture of the way they lived the notion of community. The seven examples presented here represent a range of perspective.

Thérèse has lived a sense of community based on geographic proximity and centuries of tradition and now in Sydney experiences its absence:

'not having gone to school here, I don't have family networks here ... I'm kind of lacking a connection ... coming from a small rural background where community was very definitely 'in this place' and these people and my family have lived in this house for however many ... 200 years or something'.

Now the reality of living thousands of kilometres away has 'probably challenged my notion of community’. Thérèse explains how she has deliberately gone about getting to know people socially and professionally. She has joined a surf club and met 'a whole lot of Australian women ... I guess that's the community of interest thing'. However, she has recognised that her geographic community had a life 'around the local church or the local farmers' association or whatever' and that she has had to 'go out and construct a civil participation, rather than feel naturally linked to it, but I think that's probably something people do in the big metropolitan centres'. Her volunteering with Amnesty International and Oxfam International Youth Parliament and her work in civil society organisations has led her 'over time ... [to] become part of this community of practice'. Through her work in IT, she has also become part of online communities.

James uses the metaphor of the handshake which he explains was developed by Ros Diprose [Associate Professor at University of New South Wales] to symbolise community as a reciprocated relationship. He has established the Commons Institute, a website promoting the concept of the Commons, so that there would be a space for 
people to share ideas outside of the context of 'economic man and the utilitarian'. Through this venture he 'has tried to engage in the debates'.

$\mathrm{He}$

'[doesn't] believe that we naturally form communities with anyone or civil society relationships with anyone, just based on a form of recognition ... you need to keep working at it. ... I think it has to be active or we just become strangers and I think that explains why we woke up one morning, why a lot of progressive Australians woke up one morning and saw Tampa and couldn’t understand why that had happened, you know, why the Australian public turned their back on some people who were really struggling.'

James reiterates the two inter-related ideas, that communities don't form naturally and that we have to be active to keep a sense of connection. In reference to the Commons Institute, he comments 'I'm working at it ... you have to be active'.

In Isaac's experience, too, it is possible for community to form online even when postings are anonymous. He gives the example of 4chan/b/. 4chan.org is an imageboard site, largely concerned with anime and manga. It contains many discussion boards, on topics from cooking and weapons to animated pornography, in addition to the anime and manga boards. The /b/ discussion board is 'random' and is based on the Nijiura board of the Japanese imageboard Futuba Channel. /b/tards, people who post regularly on /b/, develop memes, 'which I think comes from linguistics, units of a culture' such as the well-documented 'loooooong cat' which has 'a guy holding up a cat. And the cat is stretched out'. The memes begin with an idea or image that catches the imagination and 'all of these other people ... try to reply to that, they would change it and make it into something else and it would become a kind of in-joke, and a recurring theme, which appears over and over and this becomes a meme’. For Isaac, through this exchange of information, a sense of community can exist, even though '[people] might not have a unified set of morals or ethics'.

Sunil, like James, sees the online environment as a kind of public sphere. Here, he 'can meet and engage with people with similar interests and viewpoints as [him]self rather than being forced by the limits of current media ownership to particular opinions or 
paradigms'. Because he is able to read different perspectives or points of view, he does not feel as marginalised as he otherwise might be by 'mainstream media'. He believes that 'much of Australian media ignores people like me, who are labelled 'of ethic appearance’ or more insidiously 'of middle-eastern appearance’'. Here, his bodily identity does not intrude into his relations with others. Unlike Isaac, who is not concerned by not knowing who he is interacting with, Sunil has found himself in situations online 'which were more disturbing than in real life... as you could never know if the new person you were interacting with wasn't the same person you'd asked to leave you alone, except with a new user name'. Sunil recognises the potential anomaly of his position and relates this fear of not being able to see someone's face to the debate taking place in Britain at the time about whether Muslim women in public positions such as teaching should be able to wear the niqab, which obscures the face.

'In the UK ... there's a debate about the wearing of the niqab, the full-face veil worn by some devout Muslim women. Some politicians, like the former Foreign Secretary Jack Straw and the Prime Minister Tony Blair (as well as John Howard) have raised concerns that being unable to see someone's face makes it difficult to relate to them personally. In many ways, the internet still suffers from this.'

Katherine, who considers that community is 'a sense of commonality or togetherness based on certain criteria and recognition of that by those involved and ... some tangible way of expressing that', has 'never experienced a sense of community' online. She likens the interaction on a discussion board to:

'an interaction on a noticeboard at university. I'll post my room for let flyer and someone might deface it or they might respond to it or someone will stick their bed for sale flyer over mine ... but ... [you have to] actually see the person that tacked their flyer over someone else's flyer ... I think that would lead to an element of intrigue or perhaps community. And then you could say "Oh, it's that girl with the red hair I wonder what she does” rather than "Oh, it's a piece of paper saying bed for sale”.'

In her view, the computer-based communication is impersonal and you may never get to know 'the true person' because written communication allows one to 'create what 
you want others to see or think, it's not so immediate and spontaneous as speaking to someone directly.'

Rachel has a long-standing involvement in online communities, and believes that they 'evolve organically', and that 'to become a true community, [people] need to voluntarily create links to one another'. Yet she also notes that she often facilitates connections between people, trying 'to bring all of my contacts together, using the internet and using e-mail', giving people 'the opportunity to be part of that bigger thing'.

For Tristan, physical co-presence or its possibility is important for him to establish a relationship online with someone, although once he has made an acquaintance, he attempts to keep up contact. One of his 'bizarre ethical rules' is that he does not have any friends online that he has never met or is unlikely to meet. He thinks it is 'bordering on creepy' to make contact with someone just because they share the same interests and he favours common experience even if the experiences were not shared. He recognised this might not seem logical to an outsider:

'If you both like the same TV shows and movies you are probably going to have a fair amount in common, whereas if you both happened to have lived in Sydney, there's four and a half million people here and those connections aren't as strong, whereas in my mind they are.'

Communication technologies are important to Tristan as they are fundamental to maintaining the notion of community: 'communities were all about knowing what the other person was doing, feeling some connection to what they were doing'. This information would just be about 'ordinary things', like knowing that a friend 'Just got up, very tired, had a big night last night'. This superficial level of community is matched by the transience of relationships. Tristan's 'community changes all of the time, like at university, friendships aren’t generally formed based on long sustained interaction at the start, they are fleeting - you really only know someone for a ten to twelve week period.' 


\section{Conceptions of community}

The concepts of community intellectualised by the participants reflect the literature. It may, therefore by no coincidence that the responses sound like answers to an examination question, mirroring points that participants have learned formally. Annette refers directly to her knowledge of the scholarly debates, Isaac shows his understanding of the link between community and identity and Angela, without acknowledging it, presents the three components which Rheingold (2000) considers are fundamental to community. The participants come from a variety of study backgrounds, taking different degrees from different universities, so that the prevalence of the examination answer style of response is not a feature of a shared academic background, but may be a reflection of one of the guiding principles of their social interactions.

The seven lived examples of community can be analysed to show the overlaps with and divergences from the concepts of community documented in the literature.

Thérèse's experience of community has been one of stability, based on locality and commonality, with a long tradition of social relationships. She makes the point that community and civil society were one and the same for her. This seems to fit with the traditional view of community. Yet, when she came to Sydney as a migrant, she found herself disembedded, individualised because of the disintegration of that traditional community and thus, as Wittel (2001) proposes, she found herself in a situation where she had to take steps to construct a new set of social relationships and where for some time, her social network grew out of her work network. She also makes the point that she found it necessary to volunteer with organisations in order to re-establish herself in civil society.

James's emphasis on the reciprocated nature of community was, as he explained, linked to Ros Diprose's metaphor of the handshake and also to Marcel Mauss's idea of the gift, underpinning exchange relationships. This also has elements of a traditional view of community. The establishment of the Commons Institute derived from his concern with common ownership over ideas and the expression of ideas, again, potentially a notion that derives from a traditional view of community. Yet, his concern with the need to work at maintaining community has elements of Wittel's notion of 'catching up' with people, swapping news, updating the exchange of information (2001). It also 
has something of Nancy's notion of the need to constantly strive against the disintegration of society (1991), so that in the future, social relations that do not need to be mediated can once again exist.

Isaac's lived community is one that is based on the sharing of information, from which something new is created, and where there is no expectation that people will share values or beliefs. This might seem to be a close match for Wittel's notion of network sociality. However, this community is also one which in its relatively short history (since 2003) has created a number of stories and narratives, which have become part of the mythology of the community and beyond and this might place it alongside Sennet's narrative sociality, closer to traditional notions of community (2001).

Sunil's experience of community online mirrors Anderson's notion of the imagined community (1983; 1991). He is linked through what he reads to others whom he will probably never meet and feels a connection to them that overcomes the marginalisation he senses in his everyday life.

Katherine's concern is for the way in which people, with their emotions and vivacity, can so easily be removed from interactions, transmuted into information, as in her example of the 'girl with red hair' being replaced by a 'piece of paper' and commodified in an exchange process which values written communication above the spontaneity of conversation. Her concern with commodification, this time her own, is apparent in her description of her reasons for not persisting in her membership of the Chinese social networking site (Knorr Cetina 1997).

Rachel is not so much upset be the notion of the commodification of relationships, rather her community is one based on exchange, where what is exchanged is her social relationships, commodified and technologised into the contents of her e-mail address book or her 'Myspace friends' (Knorr Cetina 1997).

Tristan's lived experience of community closely parallels Wittel's overview of network sociality (Wittel 2001). Four of the five features that Wittel identifies are evident in Tristan's description of his lived community. The use of information and communication technologies is fundamental to Tristan's way of life. He is constantly 
creating social relationships and maintaining and updating them. His relationships with people are transient and he rarely gets to know people beyond a superficial level, exchanging information on trivial matters. He is not yet in the full time workforce, so it is not possible to comment on the blurring of the boundaries between work and play.

\section{Conclusion}

Community is a concept that the participants in this study intellectualise, which they can discuss in abstract or theoretical terms. It is something that they think about, which preoccupies them. This suggests that community is a phenomenon that still has a place in the scholarly repertoire, which needs to be thought about, considered and discussed. It is not obsolete, nor is it irrelevant as an intellectual construct.

There is not necessarily a direct parallel between the intellectualised definitions of community and the lived experiences and stories the participants tell. The definitions, mainly given as short answers, rarely contain contradictions or logical anomalies. The lived experiences of community, which emerge over the course of each interview, do not fit a single concept of community, yet this does not mean that they present a fractured or disjointed view of community. The explanations, justifications and actions of the participants all show that the notion of community is not only expressed in intellectual terms but is experienced strongly by them. It may not be over-stating the case to suggest that the stories of the lived experiences give insight into the notion of the 'good society' which Giddens (2000) suggests we seek as a result of being disembedded.

That community exists as an intellectual construct for the young people in this study is significant because without the capacity to think community, there is no capacity for them to discuss it nor to reflect on differing perspectives. These intellectualised constructs around community, however, are not merely scholarly niceties; they are related to social action and political practice in everyday life, even though the intellectualisations and lived reality may not always be a close match. Gender does not seem to have been a significant factor in shaping the understandings of community, although age and education level do appear to have been important. 
There is support from the literature (eg Onyx et al. 2005; Shah, Kwak \& Holbert 2001) for the conclusion that, to a large extent, members of Generation X and Generation $\mathrm{Y}$ experience community and related relationships differently from members of previous generations. Yet, there are also challenges to the way of thinking which allows this difference to emerge. Jenkins, for example, argues that 'Giddens privileges the preoccupations of an affluent intellectual elite as definitive of the late modern human condition' (Jenkins 2000). The participants in this study could be seen as 'intellectual', (although they might deny being 'affluent'). Further research among young people engaged in civil society online who do not have a university education could shed light on whether they are understand and experience community differently, as could research among participants who are similar in all characteristics except age.

Another aspect of this study that could warrant further exploration is the relationships that these young people have with knowledge. They use the thoughts and ideas of scholars almost as the common currency of conversation. They appear to seek information avidly through the internet and other sources for gaining additional perspectives or making decisions on their choices of social action. This information then appears to become part of them to some extent; they take on a role as a knowledgeable person and sometimes become reflexive. Beck proposes that scholarly information is used as a substitute for personal experience, particularly by 'wealthier and more protected groups' (2002, p. 53). He also suggests that, when people are faced with a plethora of interpretations, 'personality characteristics and personal networks tend to increase in importance for the practical application and utilisation of these interpretations' (2002, p. 182). Further research may be able to offer insights into the interplay of the three elements mentioned by Beck, that is, having limited personal experience because of living in a protected position in society, having limited personal experience because of youthfulness and using personal networks to suggest an appropriate meaning and action when faced with too many interpretations.

There is certainly much to indicate that participants value elements of community generally reckoned to be traditional. These include the sense of belonging, of commonality, of recognising and being recognised, of sharing a past whether through stories or experiences. This can be seen to reinforce existing scholarly notions of community. 
Yet at the same time, there is evidence of the need to shift the boundaries of those understandings. Each of the stories told here shows evidence of one or more of the elements which follow from the disembedding of individuals from their social relationships and shows to a greater or lesser extent how a person may react. These stories suggest that three possibilities for a concept of community emerge: an extension of Anderson's imagined community, which is perhaps strengthened through involvement in social networking sites such as Myspace; the network sociality proposed by Wittel as the 'paradigmatic social form of late capitalism' (2001, p. 71), or the constant striving against the disintegration of society suggested by Nancy (1991).

\section{Bibliography}

Albrow, M. \& Eade, J. 1994, 'The impact of globalization on sociological concepts: community, culture and milieu', Innovation: The European Journal of Social Sciences, vol. 7, no. 4, pp. 371-390.

Anderson, B. 1983, Imagined Communities: Reflections on the Origin and Spread of Nationalism, Verso, London.

Anderson, B. 1991, Imagined Communities: Reflections on the Origin and Spread of Nationalism, rev. edn, Verso, London.

Appadurai, A. 1990, 'Disjuncture and difference in the global cultural economy', in M. Featherstone (ed.), Global Culture: Nationalism, Globalization and Modernity, Sage, London.

Bauman, Z. 2001, Community: Seeking Safety in an Insecure World, Polity Press, Cambridge.

Beck, U. 2002, Risk Society: Towards a New Modernity, trans. M. Ritter, Sage, London.

Bell, C. \& Newby, H. 1974, 'Introduction', in C. Bell \& H. Newby (eds), The Sociology of Community, Frank Cass, London.

Cohen, A.P. 1985, The Symbolic Construction of Community, Tavistock, London.

Etzioni, A. 1995, The Spirit of Community: Rights, Responsibilities and the Communitarian Agenda, Fontana, London.

Etzioni, A. 1997, The New Golden Rule: Community and Morality in a Democratic Society, Basic Books, New York.

Geertz, C. 1993, 'Thick description: Toward an interpretive theory of culture', in, The Interpretation of Cultures; Selected Essays, Fontana, London, pp. 3-30.

Giddens, A. 1990, The Consequences of Modernity, Polity Press, Cambridge.

Giddens, A. 2000, 'The Second Globalization Debate', The Third Culture, $<$ http://www.edge.org/3rd_culture/giddens/giddens_index.html $>$.

Jenkins, R. 2000, 'Categorization: Identity, social process and epistemology', Current Sociology, vol. 48, no. 3, pp. 7-25.

Knorr Cetina, K. 1997, 'Sociality with objects: Social relations in postsocial knowledge societies', Theory, Culture and Society, vol. 14, no. 4, pp. 1-30. 
Nancy, J.-L. 1991, The Inoperative Community, trans. P. Connor, L. Garbus, M. Holland \& S. Sawhney, University of Minnesota Press, Minneapolis.

Onyx, J., Wood, C., Bullen, P. \& Osburn, L. 2005, 'Social capital: a rural youth perspective', Youth Studies Australia, vol. 24, no. 4, pp. 21-27.

Putnam, R. 2000, Bowling Alone: The Collapse and Revival of American Community, Simon and Schuster, New York.

Rheingold, H. 1994, The Virtual Community, Addison-Wesley, Reading, Mass.

Rheingold, H. 2000, The Virtual Community: Homesteading on the Electronic Frontier, Revised edn, MIT Press, Cambridge, Mass.

Shah, D.V., Kwak, N. \& Holbert, R.L. 2001, "'Connecting" and "disconnecting" with civic life: Patterns of internet use and the production of social capital', Political Communication, vol. 18, no. 2, pp. 141-162.

Tönnies, F. 1974, 'Gemeinschaft and Gesellschaft', in C. Bell \& H. Newby (eds), The Sociology of Community, Frank Cass, London.

Williams, R. 1961, The Long Revolution, Chatto and Windus, London.

Wittel, A. 2001, 'Toward a network sociality', Theory, Culture and Society, vol. 18, no. 6, pp. 51-76. 